\title{
Panorama da ocorrência de resíduos de medicamentos veterinários em leite no Brasil
}

\author{
Rosana Gomes Ferreira ${ }^{1}$, Bernardete Ferraz Spisso ${ }^{2}$, Iracema Maria de Carvalho da Hora ${ }^{3}$, \\ Mychelle Alves Monteiro ${ }^{4}$, Mararlene Ulberg Pereira ${ }^{5}$, Rafaela Pinto da Costa ${ }^{6}$, \\ Betânia de Souza Carlos ${ }^{7}$
}

O objetivo deste trabalho foi elaborar um panorama sobre a ocorrência de resíduos de medicamentos veterinários em leite no Brasil, compilando tanto os publicados por autoridades governamentais quanto por instituições acadêmicas. Os dados foram obtidos por meio de pesquisa bibliográfica. Esta pesquisa identificou 35 publicações sobre monitoramentos de resíduos de medicamentos veterinários em leite no país, das quais 34 apresentaram dados sobre o monitoramento de resíduos de antimicrobianos e 10 sobre a ocorrência de resíduos de antiparasitários. Quanto ao número de ocorrências de resíduos de antimicrobianos no leite, os beta-lactâmicos e as tetraciclinas foram os responsáveis pela maior incidência de amostras com resultados acima dos limites de detecção dos métodos empregados. 4 das 9 referências encontradas sobre monitoramentos de anfenicóis apresentaram a ocorrência de cloranfenicol e florfenicol. Apenas três referências apresentaram a ocorrência de amostras com teores acima do Limite Máximo de Resíduos (LMR), cujos analitos foram a benzilpenicilina, da classe dos beta-lactâmicos e o aminoglicosídeo estreptomicina/diidroestreptomicina. Apenas 7 (20,0\%) das referências avaliadas apresentaram resultados insatisfatórios para antimicrobianos com relação à legislação brasileira. Com relação aos antiparasitários, 5 de 10 referências (50,0\%) apresentaram resultados acima do LMR.

Palavras-chave: resíduos de medicamentos veterinários, leite, ocorrência de resíduos.

\section{Overview on veterinary drug residues ocurrence in milk in Brazil}

The objective of this work is an overview on the occurrence of veterinary drugs residues in milk in Brazil, gathering as much data as from those published by governmental authority and by academic institutions. Data were obtained through literature search. This search found 35 publications on monitoring of residues of

\footnotetext{
1 Especialista em Segurança Alimentar e Qualidade Nutricional, Laboratório de Resíduos de Medicamentos Veterinários, Departamento de Química, Instituto Nacional de Controle de Qualidade em Saúde (INCQS), Fundação Oswaldo Cruz, FIOCRUZ. Correspondência: Av. Brasil, 4365, Manguinhos, CEP 21040-360, Rio de Janeiro, RJ. E-mail: rosana.ferreira@incqs.fiocruz.br.

2 Dra. em Vigilância Sanitária, Laboratório de Resíduos de Medicamentos Veterinários, Departamento de Química, INCQS, FIOCRUZ.

${ }^{3}$ Profa. Ms. em Medicina Veterinária, Instituto Federal de Educação, Ciência e Tecnologia do Rio de Janeiro (IFRJ).

4 Ms. Ciências em Tecnologia de Processos Químicos e Bioquímicos, Laboratório de Resíduos de Medicamentos Veterinários, Departamento de Química, INCQS, FIOCRUZ.

${ }^{5}$ Especialista em Vigilância Sanitária, Laboratório de Resíduos de Medicamentos Veterinários, Departamento de Química, INCQS, FIOCRUZ.

${ }^{6}$ Mestranda em Vigilância Sanitária, INCQS, FIOCRUZ.

7 Bolsista do Programa de Inovação Tecnológica (INOVATEC), Laboratório de Resíduos de Medicamentos Veterinários, Departamento de Química, INCQS, FIOCRUZ.
} 
veterinary drugs in milk in the country, 34 out of the total presented data on the monitoring of antimicrobial residues and 10 on the occurrence of residues of antiparasitics. Regarding the number of occurrences of residues of antimicrobials in milk, the beta-lactams and the tetracyclines were responsible for the higher incidence of samples with results above the detection limits of the employed methods. 4 of 9 references found on the amphenicols monitoring showed the presence of chloramphenicol and florphenicol. Only three showed the occurrence of samples with levels above the Maximum Residue Limit (MRL), which analyte was benzylpenicillin, from the class of beta-lactam antibiotics and the aminoglycoside streptomycin/dihydrostreptomycin. Only 7 $(20.0 \%)$ of the evaluated references showed unsatisfactory results for antimicrobials with respect to Brazilian legislation. Regarding antiparasitics, 5 of 10 references (50.0\%) showed results above the MRL.

Key-words: veterinary drugs residues, milk, occurrence of residues.

\section{INTRODUÇÃO}

$\mathrm{O}$ uso de medicamentos veterinários para promover o crescimento, controlar pragas, tratar e prevenir as enfermidades do gado leiteiro pode deixar resíduos potencialmente perigosos no leite e nos derivados lácteos, quando são administrados de maneira indevida, sem respeitar as indicações dos receituários e os períodos de carência. Os principais medicamentos veterinários usados na pecuária leiteira são os antimicrobianos e antiparasitários ${ }^{[1]}$.

Os processos de pasteurização, fervura e esterilização do leite não eliminam os resíduos destes medicamentos, ocasionando problemas para a indústria e preocupação para a Saúde Pública [2].

$\mathrm{Na}$ indústria de laticínios a presença de resíduos de antimicrobianos no leite pode gerar efeitos microbiológicos indesejáveis na produção de laticínios pela inibição da flora bacteriana como a interferência das características organolépticas e tecnológicas dos produtos lácteos industrializados, causando consideráveis perdas econômicas ${ }^{[1,2]}$.

A presença de resíduos de antimicrobianos no leite é um tema de interesse para a Saúde Pública, pois estes podem desencadear reações de hipersensibilidade, alergia, resistência à antibioticoterapia, ação carcinogênica ou mutagênica, além de provocarem o surgimento de resistência bacteriana $\left[{ }^{[3]}\right.$.

No Brasil, a Instrução Normativa no 26, de 9 de julho de 2009, do Ministério da Agricultura, Pecuária e Abastecimento (MAPA) estacelece que os anfenicóis, as tetraciclinas, os beta-lactâmicos (benzilpenicilinas e cefalosporinas), as quinolonas e as sulfonamidas sistêmicas são de uso exclusivo em produtos antimicrobianos de uso veterinário, sendo vedada a sua utilização como aditivos zootécnicos melhoradores de desempenho ou como conservantes de alimentos para animais ${ }^{[4]}$.

As substâncias antiparasitárias, como as avermectinas, também são medicamentos de uso frequente na medicina veterinária para o controle de endo e/ou ectoparasitas na forma de uma ampla gama de produtos comerciais como vermífugos, larvicidas e outros, que podem acarretar problemas no processamento tecnológico de derivados do leite, sendo necessários mais estudos para avaliar seus efeitos. Para o gado de leite, existem diversas recomendações para a não utilização em vacas durante a lactação pela persistência do produto no leite [3].

As avermectinas possuem largo espectro de atividade em doses baixas e sua alta lipossolubilidade favorece a deposição no local de aplicação por via subcutânea, prolongando seu tempo de permanência no organismo. As concentrações nos fluidos orgânicos podem permanecer por longos períodos e se acumular no leite, podendo ocorrer o risco de ingestão pelos consumidores ${ }^{[5]}$.

O controle de resíduos de medicamentos veterinários, portanto, representa uma importante medida para assegurar proteção ao consumidor. No Brasil, a Instrução Normativa no 62, de 29 de dezembro de 2011, do MAPA, exige a pesquisa periódica de resíduos de antibióticos em leite, que não devem ser superiores aos Limites Máximos de Resíduos (LMRs) previstos para cada grupo químico específico [6. De acordo com a Lei no 9.782, de 26 de janeiro de 1999, é atribuição da Agência Nacional de Vigilância Sanitária (ANVISA) a regulamentação, o 
controle e a fiscalização de alimentos, no que se refere a limites de resíduos de medicamentos veterinários [7].

Os LMRs de medicamentos veterinários em alimentos de origem animal harmonizados no âmbito do Mercado Comum do Sul (MERCOSUL) pela Resolução Grupo Mercado Comum (GMC) no 54, de 29 de setembro de 2000 [8], foram internalizados no Brasil pelo MAPA através da Instrução Normativa no 12, de 10 de abril de 2001 [9]. Estas legislações citam que no caso de substâncias proibidas ou não autorizadas, uma vez que não é possível estabelecer os LMRs, são adotados níveis de ação, baseados no estado da arte das metodologias analíticas empregadas para a avaliação da conformidade dos produtos.

Existem vários métodos de análises utilizados na detecção e/ou quantificação de resíduos e contaminantes em alimentos, que podem ser divididos em métodos de triagem e de confirmação. Os métodos de triagem podem detectar a presença da substância ou classe de substâncias no nível de interesse e incluem principalmente os bioensaios, enquanto os métodos de confirmação proporcionam informações completas ou complementares para identificação e, se necessário, quantificação do analito [10].

Os métodos de triagem utilizados para determinar resíduos de medicamentos veterinários normalmente são testes baseados na inibição de crescimento microbiano, testes imunológicos e testes enzimáticos com receptores específicos, além de técnicas cromatográficas [10].

Os métodos de confirmação para análises de resíduos, de acordo com a Decisão da Comissão Europeia 657, de 12 de agosto de 2002, necessitam comprovar informações sobre a estrutura química do analito. Normalmente, são métodos que empregam as técnicas de cromatografia e espectrometria de massas [11].

A Decisão da Comissão Europeia 657/2002 prevê requisitos para os métodos analíticos utilizados em análise de amostras oficiais e especifica critérios comuns para a validação dos métodos e interpretação dos resultados analíticos de laboratórios oficiais [11].

Objetivando o controle e a vigilância dos resíduos de medicamentos veterinários nos alimentos de origem animal, o MAPA criou o Plano Nacional de
Controle de Resíduos em Produtos de Origem Animal (PNCR) e a ANVISA criou o Programa de Análises de Resíduos de Medicamentos Veterinários (PAMVet).

O PNCR, instituído pela Instrução Normativa no 42, de 20 de dezembro de 1999, regulamenta os procedimentos para o monitoramento e a investigação dos níveis de resíduos e contaminantes nos setores de carne, mel, leite e pescado ${ }^{[12]}$.

O PAMVet, iniciado em 2002, foi oficialmente instituído pela RDC no 253, de 16 de setembro de 2003 , e tem o propósito de avaliar os riscos do consumo de alimentos provenientes de animais em que foram utilizados medicamentos veterinários [13].

Como ponto de partida para efeito de interpretação dos resultados do PAMVet [14], foram considerados os LMRs de medicamentos veterinários harmonizados no MERCOSUL. Para aqueles medicamentos veterinários cujos valores de LMRs não estão estabelecidos no MERCOSUL, foram adotadas as referências internacionais na seguinte ordem: Codex Alimentarius [15], União Europeia (EU) [16] e Food and Drug Administration (FDA) [17].

O objetivo deste artigo foi traçar um panorama sobre a ocorrência de resíduos de medicamentos veterinários em leite no Brasil e avaliar quais métodos analíticos estão sendo utilizados, compilando tanto os dados publicados por autoridades governamentais quanto por instituições acadêmicas.

\section{MÉTODO}

Os dados de ocorrência de resíduos de medicamentos veterinários em leite foram obtidos através de pesquisa bibliográfica, no período de dezembro/2010 a abril/2012, nas bases Scientific Eletronic Library On Line (SciELO), PubMed, Portal de Periódicos da CAPES (Coordenação de Aperfeiçoamento de Pessoal de Nível Superior) e SciFinder Scholar. Na busca, foram utilizados os termos "monitoring", "ocurrence", "veterinary drugs in milk", "residues" e "milk". Foram selecionados os artigos publicados a partir do ano 2000 que apresentaram resultados de análises de resíduos de medicamentos veterinários em amostras de leite. 
Além de portais científicos, o levantamento bibliográfico foi realizado em periódicos impressos, no portal da ANVISA - onde estão disponíveis os relatórios do PAMVet - e no Sistema de Consulta à Legislação (SISLEGIS) do MAPA, através do qual pôde-se consultar os resultados do PNCR.

\section{RESULTADOS E DISCUSSÃO}

Esta pesquisa identificou 35 publicações sobre análises de resíduos de medicamentos veterinários em leite, das quais 34 apresentaram dados sobre pesquisa de resíduos de antimicrobianos e 10 sobre a ocorrência de resíduos de antiparasitários, sendo que das 35 referências, 9 apresentaram resultados de monitoramentos de resíduos de antimicrobianos e antiparasitários, simultaneamente. A distribuição, por classe, do total de publicações encontradas com dados de análises de resíduos de antimicrobianos está ilustrado na Figura. De acordo com os resultados da pesquisa realizada, percebe-se que os $\beta$-lactâmicos e as tetraciclinas foram as classes de antimicrobianos mais monitoradas no leite, seguidas das sulfonamidas, dos anfenicóis e dos aminoglicosídeos, dos macrolídeos, e por último, das quinolonas e trimetoprima.

Figura. Distribuição do total de publicações encontradas com dados de análises de resíduos de antimicrobianos em leite no Brasil divididos por classe de antimicrobianos

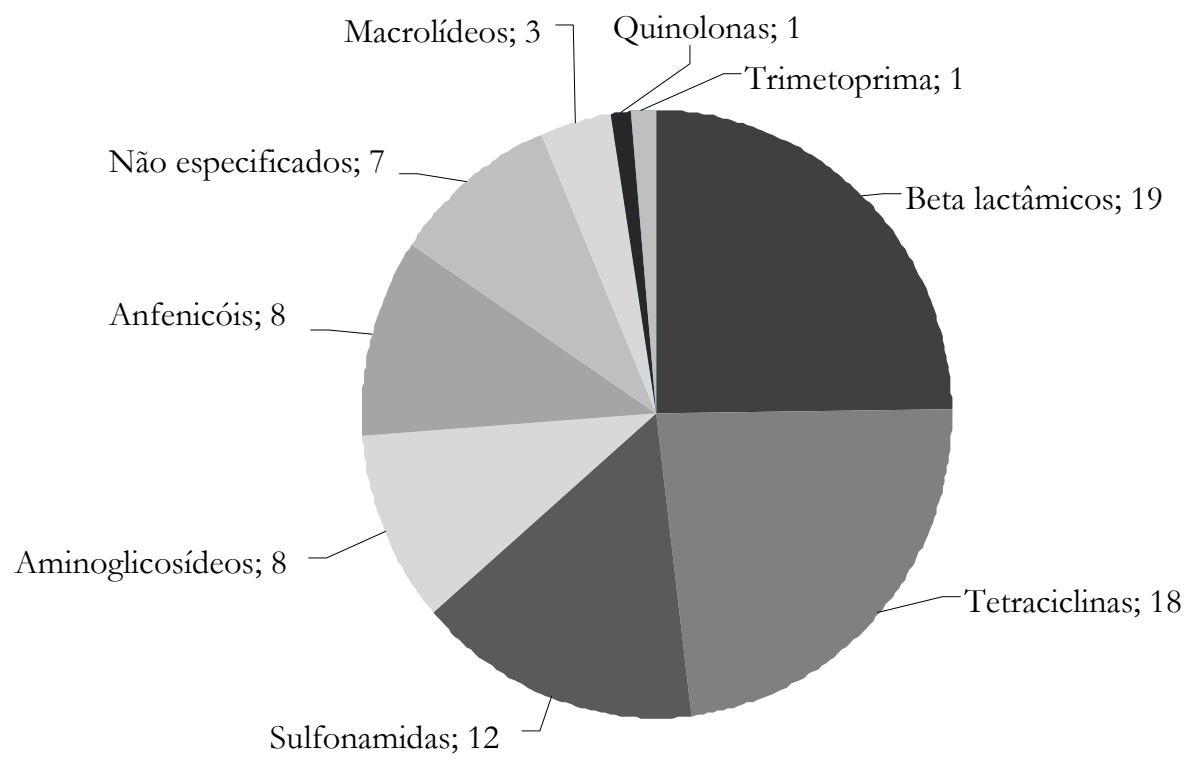

Avaliando-se os métodos analíticos utilizados nos monitoramentos, observou-se que em sua maioria foram empregados métodos de triagem para avaliar os resíduos de antimicrobianos no leite, embora nem todas as referências estudadas apresentassem o método analítico utilizado. A Tabela 1 mostra os testes analíticos e kits comerciais utilizados nas análises de triagem dos trabalhos pesquisados.

Foi verificado que os antimicrobianos das classes dos $\beta$-lactâmicos e das tetraciclinas foram os que apresentaram maior variedade de métodos analíticos de triagem por kits comerciais, os quais foram o Charm - Test TM (Charm Science Incorporation, EUA) [18], Charm SL - Test TM (Charm Science Incorporation, EUA) [19], Teste Copan CH ATK ${ }^{\circledR}$ (Copan Italia Spa, Itália) [19], Delvotest - $P{ }^{\circledR}$ (Gist Brocades, Holanda) [20,21], Delvotest $S P^{\circledR}$ (Gist Brocades, Holanda) ${ }^{[14,22-24]}$ e Snap Test ${ }^{\circledR}$ (Idexx Laboratories, EUA) [5,14,19,20,25-30].

Para a determinação de gentamicina, antibiótico da classe dos aminoglicosídeos, foram citados três métodos analíticos de triagem por kits comerciais: o SNAP Gentamicin ${ }^{\circledR}$ (Idexx Laboratories, 
Tabela 1. Testes analíticos e kits comerciais utilizados nas análises de triagem dos trabalhos pesquisados

\begin{tabular}{|c|c|c|c|c|}
\hline $\begin{array}{l}\text { Método } \\
\text { Analítico }\end{array}$ & Testes e kits comerciais & $\begin{array}{c}\text { Classes de } \\
\text { antimicrobianos } \\
\text { detectadas } \\
\end{array}$ & Referências & $\begin{array}{c}\text { Total de } \\
\text { trabalhos } \\
\text { por método } \\
\end{array}$ \\
\hline \multirow{13}{*}{$\begin{array}{l}\text { Inibição do } \\
\text { crescimento } \\
\text { microbiano }\end{array}$} & $\begin{array}{c}\text { ADM }{ }^{\circledR}-\text { Antimicrobial Diffusion Method } \\
\text { (Chr. Hansen S.A., Peru) }\end{array}$ & NE & 37 & 1 \\
\hline & $\begin{array}{c}\text { Charm - Test TM } \\
\text { (Charm Science Incorporation, EUA) }\end{array}$ & $\begin{array}{c}\text { Aminoglicosídeo } \\
\text { Beta-lactâmicos } \\
\text { Macrolídeo } \\
\text { Tetraciclinas } \\
\text { Sulfonamidas }\end{array}$ & 18 & 1 \\
\hline & $\begin{array}{c}\text { Copan } C H A T K{ }^{\circledR} \\
\text { (Copan Italia Spa, Itália) }\end{array}$ & $\begin{array}{l}\text { Beta-lactâmicos } \\
\text { Tetraciclinas } \\
\text { Sulfonamidas }\end{array}$ & 19 & 1 \\
\hline & $\begin{array}{c}\text { Delvotest }-P^{\circledR} \\
\text { (Gist Brocades, Holanda) }\end{array}$ & $\begin{array}{l}\text { Beta-lactâmicos } \\
\text { Tetraciclinas } \\
\text { Sulfonamidas }\end{array}$ & 20,21 & 2 \\
\hline & $\begin{array}{c}\text { Delvotest }-S P^{\circledR} \\
\text { (Gist Brocades, Holanda) }\end{array}$ & $\begin{array}{l}\text { Aminoglicosíedo } \\
\text { Beta-lactâmicos }\end{array}$ & $\begin{array}{c}14,22,23 \\
24\end{array}$ & 4 \\
\hline & $\begin{array}{c}\text { Delvotest-SP/SP Mini }{ }^{\circledR} \\
\text { (DSM Food Specialties Ingredients, Holanda) }\end{array}$ & NE & 48 & 1 \\
\hline & $\begin{array}{c}\text { Eclipse } 50{ }^{\circledR} \\
\text { (Cap-Lab Indústria e Comércio Ltda., Brasil) }\end{array}$ & NE & 35 & 1 \\
\hline & Método do disco em placa & $\mathrm{NE}$ & $32,33,34$ & 3 \\
\hline & Método do iogurte & $\mathrm{NE}$ & 36 & 1 \\
\hline & $\begin{array}{c}\text { Charm SL-Test TM } \\
\text { (Charm Science Incorporation, EUA) }\end{array}$ & $\begin{array}{l}\text { Beta-lactâmicos } \\
\text { Tetraciclinas } \\
\text { Sulfonamidas }\end{array}$ & 19 & 1 \\
\hline & $\begin{array}{l}\text { Cite Probe Gentamicin Test }{ }^{\circledR} \\
\text { (Idexx Laboratories, EUA) }\end{array}$ & Aminoglicosídeo & 20 & 1 \\
\hline & $\begin{array}{c}\text { ELA neomycin }{ }^{\circledR} \\
\text { (Euro-Diagnostica, Holanda) }\end{array}$ & Aminoglicosídeo & $5,27,28,30$ & 4 \\
\hline & $\begin{array}{l}\text { Ridascreen chloramphenicol }{ }^{\circledR} \\
\text { (R-Biopharm, Alemanha) }\end{array}$ & Anfenicol & $5,27,28,30$ & 4 \\
\hline \multirow[t]{4}{*}{ ELISA } & $\begin{array}{l}\text { Ridascreen streptomycin }{ }^{\circledR} \\
\text { (R-Biopharm, Alemanha) }\end{array}$ & Aminoglicosídeo & $\begin{array}{l}5,26,27,28 \\
30,31\end{array}$ & 6 \\
\hline & $\begin{array}{c}\text { Snap beta-lactam Test }{ }^{\circledR} \\
\text { (Idexx Laboratories, EUA) }\end{array}$ & Beta-lactâmicos & $\begin{array}{c}5,20,25,26 \\
27,28,29 \\
30\end{array}$ & 8 \\
\hline & $\begin{array}{l}\text { Snap gentamicin Test }{ }^{\circledR} \\
(\text { Idexx Laboratories, EUA) }\end{array}$ & Aminoglicosídeo & 27,28 & 2 \\
\hline & $\begin{array}{l}\text { Snap tetracycline Test }{ }^{\circledR} \\
\text { (Idexx Laboratories, EUA) }\end{array}$ & Tetraciclinas & $\begin{array}{c}5,14,19,20 \\
26,27,28, \\
30\end{array}$ & 8 \\
\hline
\end{tabular}

NE: não especificado. 
EUA) [27,28], O Charm - Test TM (Charm Science Incorporation, EUA) [18] e o Cite Probe Gentamicin Test ${ }^{\circledR}$ (Idexx Laboratories, EUA) [18,20].

Apenas um método analítico de triagem foi citado para a determinação dos aminoglicosídeos estreptomicina/diidroestreptomicina e neomicina, do anfenicol cloranfenicol e do macrolídeo tilosina. Tais métodos foram os kits comerciais Ridascreen streptomycin ${ }^{\circledR}$ (R-Biopharm, Alemanha) [26-28,30,31], ELA neomycin ${ }^{\circledR}$ (Euro-Diagnostica, Holanda) [5,27,28,30], Ridascreen chloramphenicol ${ }^{\circledR}$ (R-Biopharm, Alemanha) $[5,26,27,28,30,31] \mathrm{e}$ Charm - Test TM (Charm Science Incorporation, EUA) [18], respectivamente.

Os kits comerciais Charm - Test TM (Charm Science Incorporation, EUA) [18], Copan $\mathrm{CH}^{\mathrm{ATTK}}{ }^{\circledR}{ }^{\circledR}$ Copan Italia Spa, Itália) [19], Charm SL - Test TM (Charm Science Incorporation, EUA) ${ }^{[19]}$ e Delvotest - SP/SP Mini ${ }^{\circledR}$ (DSM Food Specialties Ingredients, Holanda) [21] também foram citados como métodos analíticos na determinação de sulfonamidas.

Outros métodos analíticos de triagem, como por exemplo, o método do disco em placa [32-34], o kit comercial Eclipse $50{ }^{\circledR}$ (Cap-Lab Indústria e Comércio Ltda, Brasil) [35], o método do iogurte [36] e $A D M^{\circledR}$ Antimicrobial Diffusion Method (Chr. Hansen S.A., Peru) [37], foram citados sem especificar quais antimicrobianos detectam.

Os métodos analíticos Delvotest $\mathrm{P} / \mathrm{SP}{ }^{\circledR}, A D M$ ${ }^{\circledR}$, Eclipse $50{ }^{\circledR}$, Copan $C H A T K{ }^{\circledR}$, método do disco em placa e do iogurte são testes baseados na inibição de crescimento microbiano. Nestes testes a amostra de leite é colocada em contato com um micro-organismo sensível. Adicionam-se nutrientes e, após um período de incubação, se houver a presença de resíduos na amostra, observa-se a ausência do crescimento microbiano. $\mathrm{Na}$ ausência de resíduo, o crescimento microbiano é evidenciado pela produção de ácido, pela redução de corantes ou pela formação de uma camada visível de crescimento na superfície de Agar [23].

Os kits Delvotest P, SP, SP/SP Mini ${ }^{\circledR}, A D M{ }^{\circledR}$, Copan $C H$ ATK ${ }^{\circledR}$ e Eclipse $50{ }^{\circledR}$ são baseados no crescimento rápido e produção de ácido pelo Bacillus stearothermophilus var. colidolactis - para os 5 primeiros kits - e Geobacillus stearothermophilus - para o último - com consequente mudança de coloração do indicador ácidobase, como por exemplo, o corante púrpura de bromocresol $[19,23,33,37]$.
O método do disco em placa também se utiliza de placas de Agar com o micro-organismo B. stearothermophilus var. colidolactis ou Bacillus subtilis. Se na amostra houver resíduos de antibióticos, o microorganismo não se desenvolve apresentando um halo de inibição [33].

O método do iogurte baseia-se na inibição da formação de ácido pelo Streptococcus thermopbilus e Lactobacillus bulgaricus, que são micro-organismos tipicamente usados na cultura "starter" da fabricação de iogurtes. $\mathrm{Na}$ ausência de antimicrobianos, o processo fermentativo ocorre normalmente, havendo diminuição do $\mathrm{pH}$ e coagulação do leite, além de mudança de coloração do indicador ${ }^{[3]}$.

Os testes Cite Probe ${ }^{\circledR}$, Charm SL-Test TM, Snap Test ${ }^{\circledR}, E L A$ neomycin ${ }^{\circledR}$ e Ridascreen ${ }^{\circledR}$ são métodos imunológicos baseados na reação dos antimicrobianos (antígeno) com um anticorpo ou receptor específico $[18,20,27]$. Os testes que utilizam este princípio empregam substâncias radioativas ou enzimas, na técnica conhecida como ELISA (Enrime Linked ImmunoSorbent Assay). Nestes testes, quando uma amostra possui resíduos de antimicrobianos, há alteração de cor, devido à reação da enzima com o substrato.

As principais vantagens destes testes são seu baixo custo, a facilidade de execução e a possibilidade de diversas amostras poderem ser analisadas simultaneamente. Como desvantagem, os bioensaios fornecem apenas análises semiquantitativas, e podem dar origem a resultados falsos positivos ${ }^{[10]}$.

Diferentes técnicas cromatográficas foram apresentadas para a análise de resíduos de antimicrobianos e antiparasitários em leite. Estas técnicas estão descritas na Tabela 2. Para antimicrobianos, algumas destas técnicas foram utilizadas na triagem e outras para análise direta ou como métodos de confirmação. A técnica de Cromatografia Líquida de Alta Eficiência acoplada à Espectrometria de Massas (CLAE-EM) foi utilizada na análise direta do macrolídeo eritromicina [5]. Com relação aos aminoglicosídeos Estreptomicina e Diidroestreptomicina (ESTP e DESTP), a técnica de Cromatografia Líquida acoplada a um Espectrômetro de Massas Sequencial (CLAE-EM/EM), com ionização química à pressão atmosférica (APCI, Atmospheric Pressure Chemical Ionization) e analisadores de massa do tipo quadrupolo por tempo de voo (QTof, Quadrupolo Time-offlight) foi utilizada como método 
Tabela 2. Técnicas cromatográficas apresentadas para a análise de resíduos de antimicrobianos e antiparasitários em leite

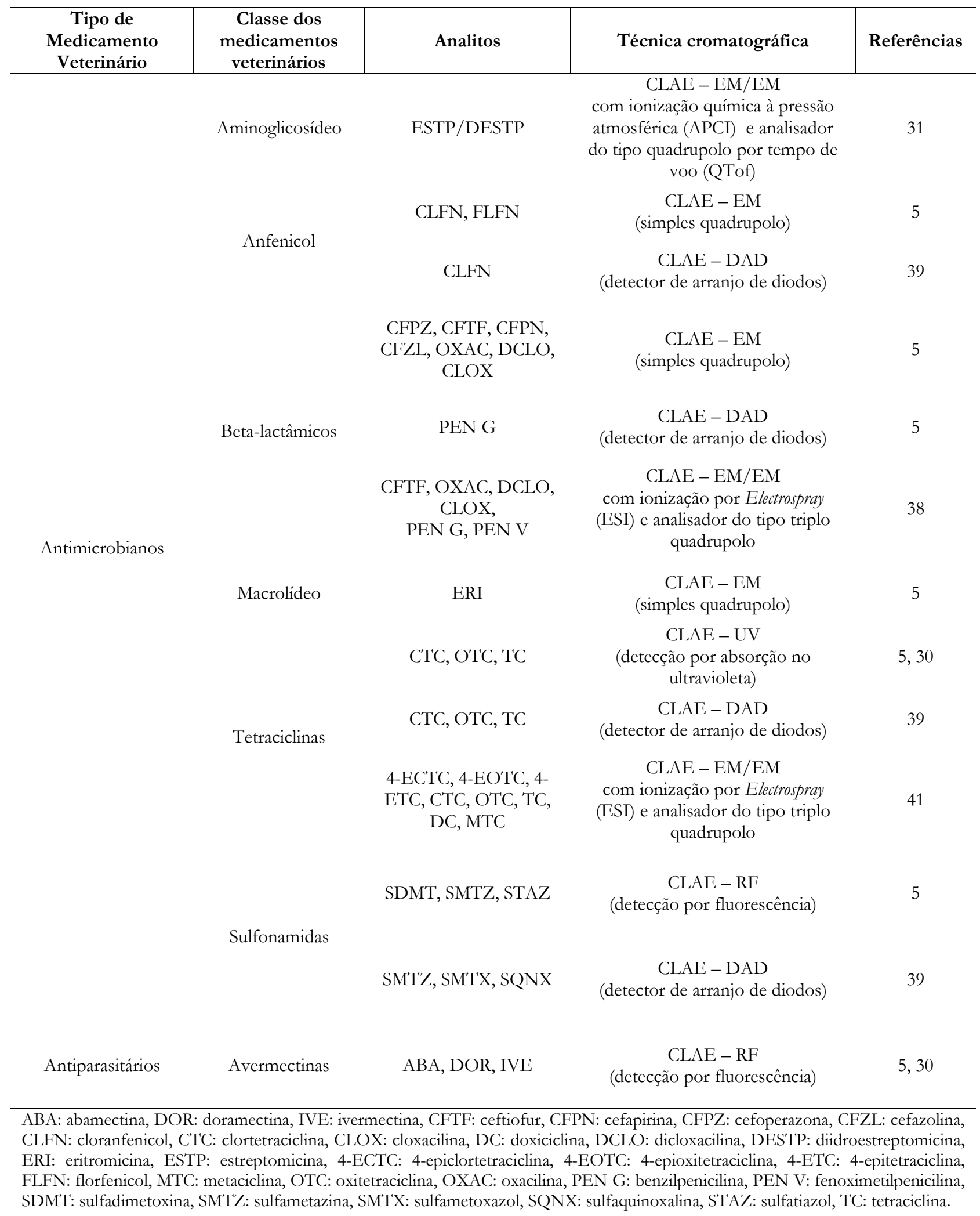


de confirmação [30]. Segundo o relatório do PAMVet referente às atividades de 2006 a 2007, utilizou-se a técnica de CLAE-EM com analisador de simples quadrupolo para confirmação qualitativa de $\beta$ lactâmicos da sub-classe das cefalosporinas e para análise de confirmação, quantitativa, de anfenicóis [5], Também foi apresentada a técnica de CLAE-EM/EM com ionização por Electrospray (ESI) e analisadores de massa do tipo triplo quadrupolo para a análise de confirmação quantitativa de $\beta$-lactâmicos ${ }^{[38]}$. A técnica de Cromatografia de Alta Eficiência com Detector de Arranjo de Diodos (CLAE-DAD) foi utilizada na análise direta de anfenicóis, sulfonamidas e tetraciclinas, simultaneamente ${ }^{[39]}$, e de penicilina $G{ }^{[40]}$. Em outra pesquisa, utilizou-se a técnica de CLAE com detecção por fluorescência para análise direta de sulfonamidas [5]. $\mathrm{Na}$ determinação de tetraciclinas foram citadas as técnicas cromatográficas CLAE-EM/EM com ionização por Electrospray (ESI) e analisador do tipo triplo quadrupolo para análise direta e como método de confirmação [41] e CLAE com detecção por absorção no ultravioleta para análise de triagem [5,30].

Para a determinação de avermectinas, a técnica de CLAE com detecção por fluorescência foi o único método analítico apresentado [5,30,42], embora somente 3 das 10 publicações encontradas sobre monitoramentos de antiparasitários tenham especificado o método analítico utilizado.

Uma das vantagens dos métodos cromatográficos sobre os kits comerciais é a capacidade de identificar os compostos individualmente. As técnicas cromatográficas são métodos analíticos mais específicos e seletivos. Como desvantagens podem ser citadas o elevado custo de aquisição, operação e manutenção da instrumentação e maior tempo de análise em relação aos kits comerciais.

O acoplamento da cromatografia líquida com a espectrometria de massas apresenta vantagens, como o fato de ter alta seletividade, quando se opera no modo de monitoramento de íon selecionado, o qual permite a identificação e a quantificação de picos sobrepostos; a boa detectabilidade; a possibilidade de avaliação da pureza do pico; a confirmação da presença do analito mediante a informação de massa molar e estrutural, sendo essa a característica mais relevante. Apesar do alto custo, o uso do espectrômetro de massas em CLAE está tornando-se mais comum [10].

A Decisão da Comissão Europeia 657/2002, estabelece que métodos de confirmação para resíduos ou contaminantes orgânicos necessitam fornecer informações sobre a estrutura química do analito [11]. Várias técnicas ou combinações de técnicas são consideradas adequadas para a identicação dos compostos. Além disso, se uma única técnica não possuir especificidade suficiente, a identificação pode ser alcançada pela combinação adequada de diferentes técnicas ${ }^{[10]}$.

Segundo Blasco et al. [10], as técnicas de detecção de diodos e fluorimétricas estão caindo em desuso, embora a Decisão da Comissão Europeia 657/2002 ainda as mantenha como possíveis técnicas de confirmação para antimicrobianos específicos. Existem ainda alguns trabalhos usando detecção por Ultravioleta (UV), mas como método de triagem. Hoje em dia, a confirmação de resíduos de antibióticos em alimentos é executada por CLAE-EM, principalmente CLAE-EM/EM.

Ambos os métodos de triagem e confirmação têm suas exigências específicas, as quais devem ser consideradas quando selecionada uma técnica analítica apropriada. O desenvolvimento, a otimização, e a validação de métodos analíticos adequados são elementos importantes para garantir a confiabilidade dos ensaios de resíduos de medicamentos veterinários.

Nas publicações encontradas avaliaram-se dados sobre os analitos, total de amostras analisadas, número de amostras com resultados acima do Limite de Detecção (LD) e acima do LMR, tipo de leite, região e períodos dos monitoramentos. Estes dados foram registrados na Tabela 3, para os antimicrobianos e na Tabela 4, para os antiparasitários.

Quanto ao número de ocorrências de resíduos de antimicrobianos no leite, muitas das publicações pesquisadas não especificaram quais analitos ou classes foram detectadas. Entre as que especificaram, os $\beta$ lactâmicos e as tetraciclinas foram os responsáveis pela maior incidência de amostras com resultados acima dos LD. Porém, nem todas estas amostras foram submetidas a métodos de confirmação e para as que foram, nem todos os analitos puderam ser confirmados.

Oliveira et al. [31] relataram que das 299 amostras analisadas apenas 2 apresentaram resíduos de estreptomicina/diidroestreptomicina na análise de triagem, mas não foram confirmadas por CLAE$\mathrm{EM} / \mathrm{EM}$. 
Tabela 3. Resultado dos monitoramentos de antimicrobianos relatados nas referências estudadas

\begin{tabular}{|c|c|c|c|c|c|c|c|c|}
\hline Classes & Analitos & $\begin{array}{c}\text { Total de } \\
\text { amostras } \\
\text { analisadas }\end{array}$ & $\begin{array}{l}\text { Total de } \\
\text { amostras } \\
\text { com } \\
\text { resíduos } \\
\text { acima do } \\
\text { LD } \\
(\%)\end{array}$ & $\begin{array}{l}\text { Total de } \\
\text { amostras } \\
\text { com } \\
\text { resíduos } \\
\text { acima do } \\
\text { LMR } \\
(\%)\end{array}$ & $\begin{array}{l}\text { Tipo } \\
\text { de leite }\end{array}$ & Estado & $\begin{array}{c}\text { Período } \\
\text { do } \\
\text { monitoramento }\end{array}$ & Referência \\
\hline $\begin{array}{l}\text { Aminoglicosídeos } \\
\beta \text {-lactâmicos } \\
\text { Macrolídeos } \\
\text { Sulfanamidas } \\
\text { Tetraciclinas }\end{array}$ & $\begin{array}{l}\text { GEN, } \\
\text { AMOX, } \\
\text { AMPI, } \\
\text { CFTF, } \\
\text { CFPN, } \\
\text { PEN G, } \\
\text { TIL, } \\
\text { SDMT, } \\
\text { SMTZ, } \\
\text { OTC }\end{array}$ & 210 & $24(11,4 \%)$ & $\mathrm{NE}$ & cru & $\begin{array}{l}\text { MG, RS, } \\
\text { PR, SP }\end{array}$ & $\mathrm{NE}$ & 18 \\
\hline $\begin{array}{l}\beta \text {-lactâmicos } \\
\text { Sulfonamidas } \\
\text { Tetraciclinas }\end{array}$ & $\mathrm{NE}$ & 103 & $11(10,7 \%)$ & $\mathrm{NE}$ & Cru & PA & 2002 a 2004 & 19 \\
\hline $\begin{array}{c}\text { Aminoglicosídeos } \\
\beta \text {-lactâmicos } \\
\text { Tetraciclinas }\end{array}$ & $\begin{array}{l}\text { GEN, } \\
\text { AMOX, } \\
\text { AMPI, } \\
\text { CFPN, } \\
\text { CFTF, } \\
\text { PEN G, } \\
\text { CTC, } \\
\text { OTC, } \\
\text { TC }\end{array}$ & 300 & $13(4,3 \%)$ & $\mathrm{NE}$ & $\begin{array}{l}\text { pasteurizado } \\
\text { e integral } \\
\text { fazenda }\end{array}$ & RJ & 1996 a 1997 & 20 \\
\hline $\begin{array}{l}\beta \text {-lactâmicos } \\
\text { Sulfonamidas } \\
\text { Tetraciclinas }\end{array}$ & $\begin{array}{l}\text { CLOX, } \\
\text { PEN G, } \\
\text { SMDN, } \\
\text { TC }\end{array}$ & 21 & $7(33,3 \%)$ & $\mathrm{NE}$ & Cru & MG & $\mathrm{NE}$ & 21 \\
\hline $\begin{array}{c}\text { Anfenicol } \\
\text { Sulfonamidas } \\
\text { Tetraciclinas }\end{array}$ & $\begin{array}{l}\text { CLFN, } \\
\text { SMTZ, } \\
\text { SMTX, } \\
\text { SQNX, } \\
\text { CTC, } \\
\text { OTC, } \\
\text { TC }\end{array}$ & 60 & $0(0)$ & $0(0)$ & pasteurizado & SP & 2006 & 39 \\
\hline $\begin{array}{c}\text { Aminoglicosídeos } \\
\text { Anfenicol } \\
\beta \text {-lactâmicos } \\
\text { Macrolídeo } \\
\text { Sulfonamidas } \\
\text { Tetraciclinas }\end{array}$ & $\begin{array}{c}\text { ESTP, } \\
\text { NEO, } \\
\text { CLFN, } \\
\text { PEN G, } \\
\text { ERI, } \\
\text { CTC, } \\
\text { OTC, } \\
\text { TC }\end{array}$ & 99 & $0(0)$ & $0(0)$ & $\mathrm{NE}$ & $\mathrm{NE}$ & 2006 & 44 \\
\hline
\end{tabular}

Continua 
Tabela 3. Continuação

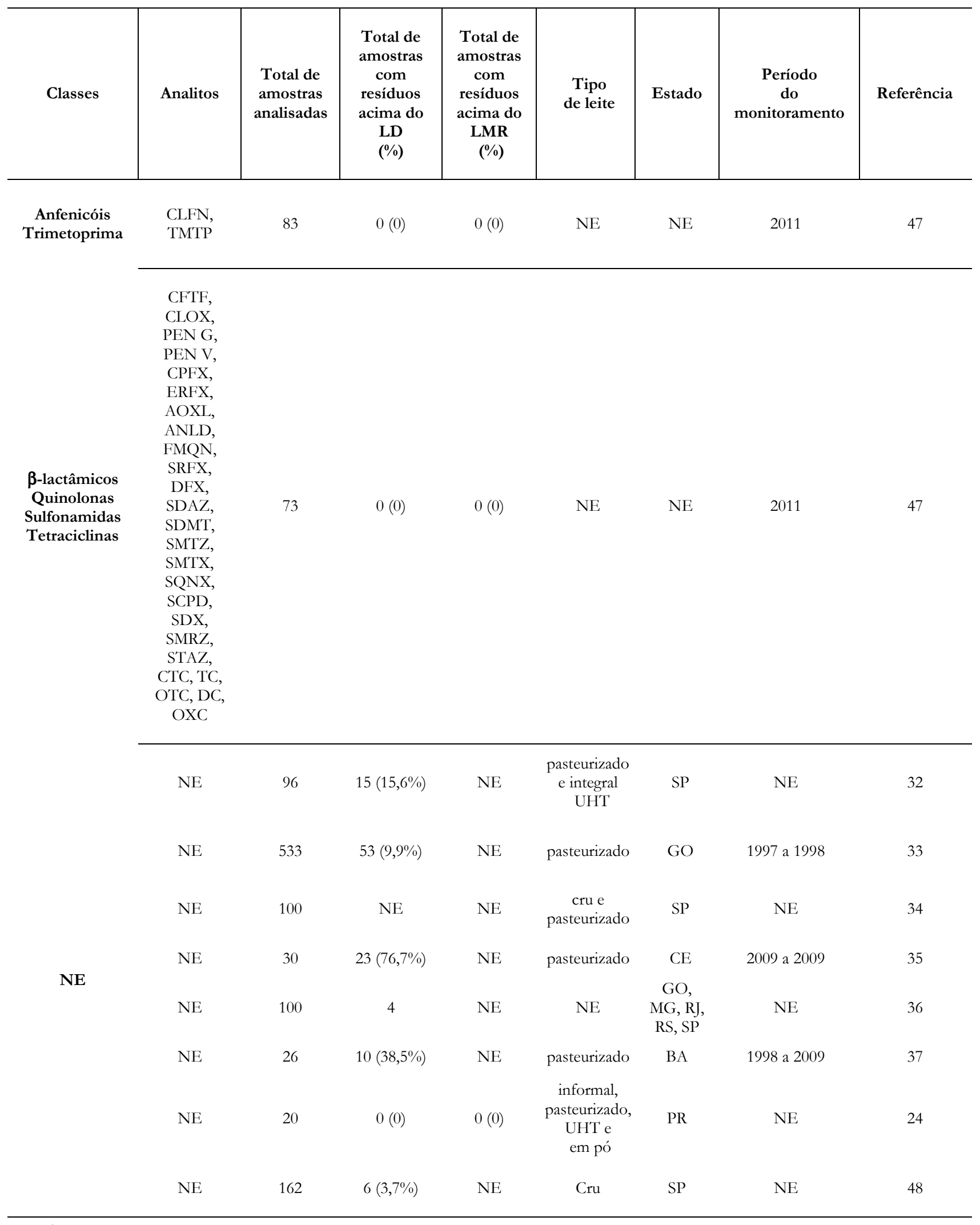

Continua 
Tabela 3. Continuação

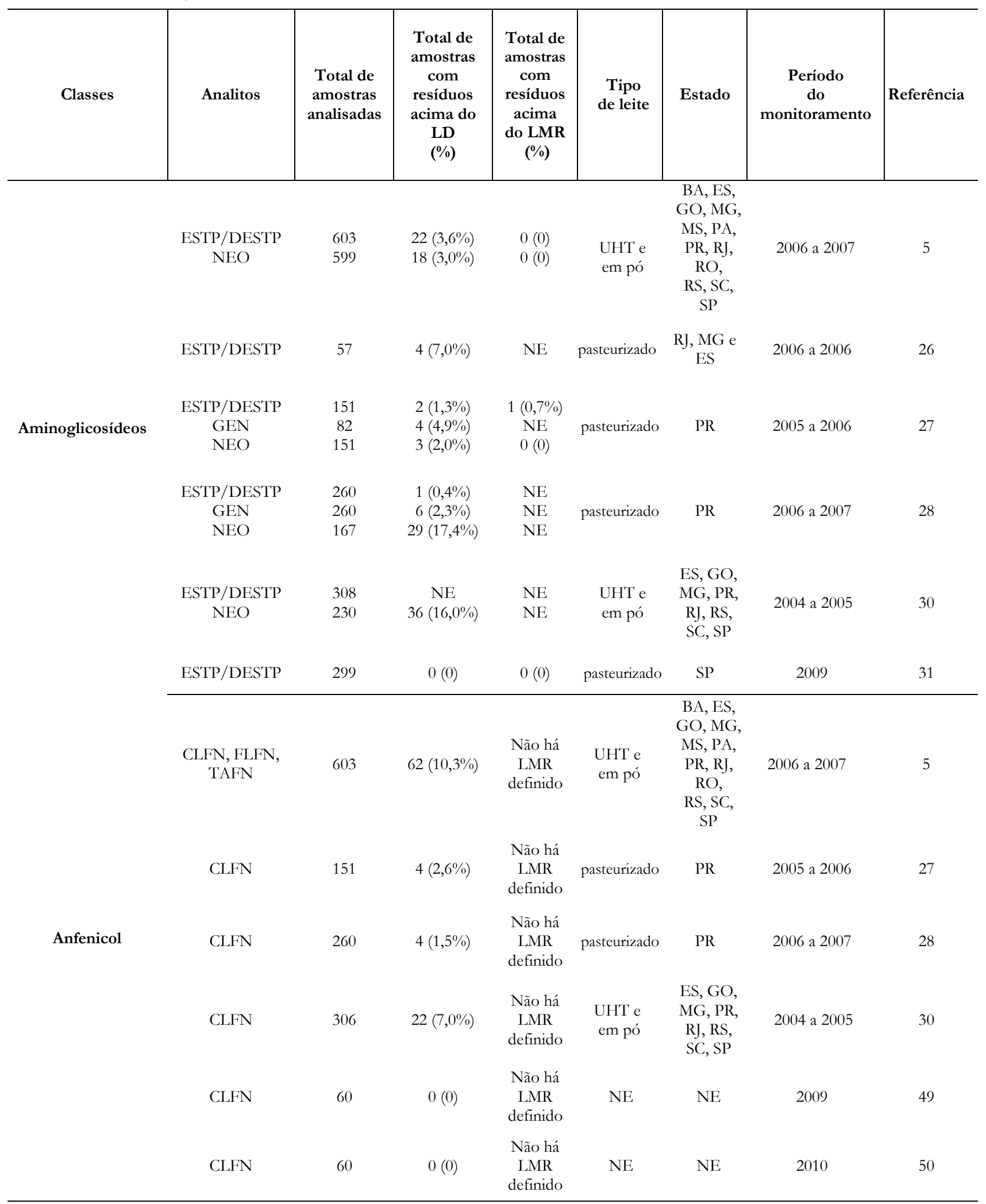

Continua 
Tabela 3. Continuação

\begin{tabular}{|c|c|c|c|c|c|c|c|c|}
\hline Classes & Analitos & $\begin{array}{c}\text { Total de } \\
\text { amostras } \\
\text { analisadas }\end{array}$ & $\begin{array}{c}\text { Total de } \\
\text { amostras } \\
\text { com } \\
\text { resíduos } \\
\text { acima do } \\
\text { LD } \\
(\%)\end{array}$ & $\begin{array}{c}\text { Total de } \\
\text { amostras } \\
\text { com } \\
\text { resíduos } \\
\text { acima do } \\
\text { LMR } \\
(\%)\end{array}$ & $\begin{array}{l}\text { Tipo } \\
\text { de leite }\end{array}$ & Estado & $\begin{array}{c}\text { Período } \\
\text { do } \\
\text { monitoramento }\end{array}$ & Referência \\
\hline & $\begin{array}{l}\text { AMOX, AMPI, } \\
\text { CFTF, CFPN, } \\
\text { CFPZ, CFZL } \\
\text { CLOX, DCLO, } \\
\text { OXAC, PEN G }\end{array}$ & 607 & $6(1,0 \%)$ & $0(0)$ & $\begin{array}{l}\text { UHT e } \\
\text { em pó }\end{array}$ & $\begin{array}{c}\text { BA, ES, } \\
\text { GO, MG, } \\
\text { MS, PA, } \\
\text { PR, RJ, } \\
\text { RO, } \\
\text { RS, SC, } \\
\text { SP }\end{array}$ & 2006 a 2007 & 5 \\
\hline & $\begin{array}{l}\text { AMOX, AMPI } \\
\text { CFTF, PEN G }\end{array}$ & 730 & $0(0)$ & $0(0)$ & $\begin{array}{l}\text { UHT e } \\
\text { em pó }\end{array}$ & $\begin{array}{c}\text { ES, MG, } \\
\text { PR, RJ, } \\
\text { RS, SC, } \\
\text { SP }\end{array}$ & 2002 a 2003 & 14 \\
\hline & $\begin{array}{l}\text { AMOX, AMPI } \\
\text { CFTF, PEN G }\end{array}$ & 32 & $0(0)$ & $0(0)$ & Cru & $\mathrm{RN}$ & $\mathrm{NE}$ & 22 \\
\hline & $\mathrm{NE}$ & 50 & $5(10,0 \%)$ & NE & $\begin{array}{l}\text { pronto para } \\
\text { consumo e } \\
\text { tanques } \\
\text { refrigeradores }\end{array}$ & SP & 2004 & 23 \\
\hline & $\begin{array}{c}\text { AMOX, AMPI, } \\
\text { CFTF, CFPN, } \\
\text { PEN G }\end{array}$ & 10464 & $121(1,16 \%)$ & NE & Cru & RS & 1998 a 1999 & 25 \\
\hline & $\mathrm{NE}$ & 57 & $8(14,0 \%)$ & $\mathrm{NE}$ & pasteurizado & $\begin{array}{c}\text { RJ, MG e } \\
\text { ES }\end{array}$ & 2006 a 2006 & 26 \\
\hline \multirow[t]{8}{*}{$\underset{\text { lactâmicos }}{\beta-}$} & $\begin{array}{l}\text { AMOX, AMPI, } \\
\text { CFPN, CFTF, } \\
\text { PEN G }\end{array}$ & 151 & $5(3,3 \%)$ & $\mathrm{NE}$ & pasteurizado & PR & 2005 a 2006 & 27 \\
\hline & $\begin{array}{c}\text { AMOX, AMPI, } \\
\text { CFPN, CFTF, } \\
\text { PEN G }\end{array}$ & 260 & $9(3,5 \%)$ & $\mathrm{NE}$ & pasteurizado & PR & 2006 a 2007 & 28 \\
\hline & $\begin{array}{l}\text { AMOX, AMPI, } \\
\text { CFLP, CLOX, } \\
\text { PEN G }\end{array}$ & 158 & $3(1,9 \%)$ & $\mathrm{NE}$ & Cru & MG & NE & 29 \\
\hline & $\mathrm{NE}$ & 312 & $3(1,0 \%)$ & $0(0)$ & $\begin{array}{l}\text { UHT e } \\
\text { em pó }\end{array}$ & $\begin{array}{l}\text { ES, GO, } \\
\text { MG, PR, } \\
\text { RJ, RS, } \\
\text { SC, SP }\end{array}$ & 2004 a 2005 & 30 \\
\hline & PEN G & 96 & $33(34,4 \%)$ & $\mathrm{NE}$ & $\begin{array}{l}\text { pasteurizado } \\
\text { e integral } \\
\text { UHT }\end{array}$ & SP & $\mathrm{NE}$ & 32 \\
\hline & $\mathrm{NE}$ & 30 & $0(0)$ & $0(0)$ & Cru & $\mathrm{PB}$ & $\mathrm{NE}$ & 51 \\
\hline & PEN G & 43 & $36(83,7 \%)$ & $16(37,2 \%)$ & pasteurizado & RJ & $\mathrm{NE}$ & 40 \\
\hline & $\begin{array}{l}\text { AMOX, AMPI, } \\
\text { CFPZ, CFZL, } \\
\text { CFLX, CFTF, } \\
\text { CLOX, DCLO, } \\
\text { OXAC, PEN G }\end{array}$ & 84 & $1(1,2 \%)$ & $1(1,2 \%)$ & Cru & $\mathrm{NE}$ & $\mathrm{NE}$ & 38 \\
\hline
\end{tabular}

Continua 
Tabela 3. Continuação

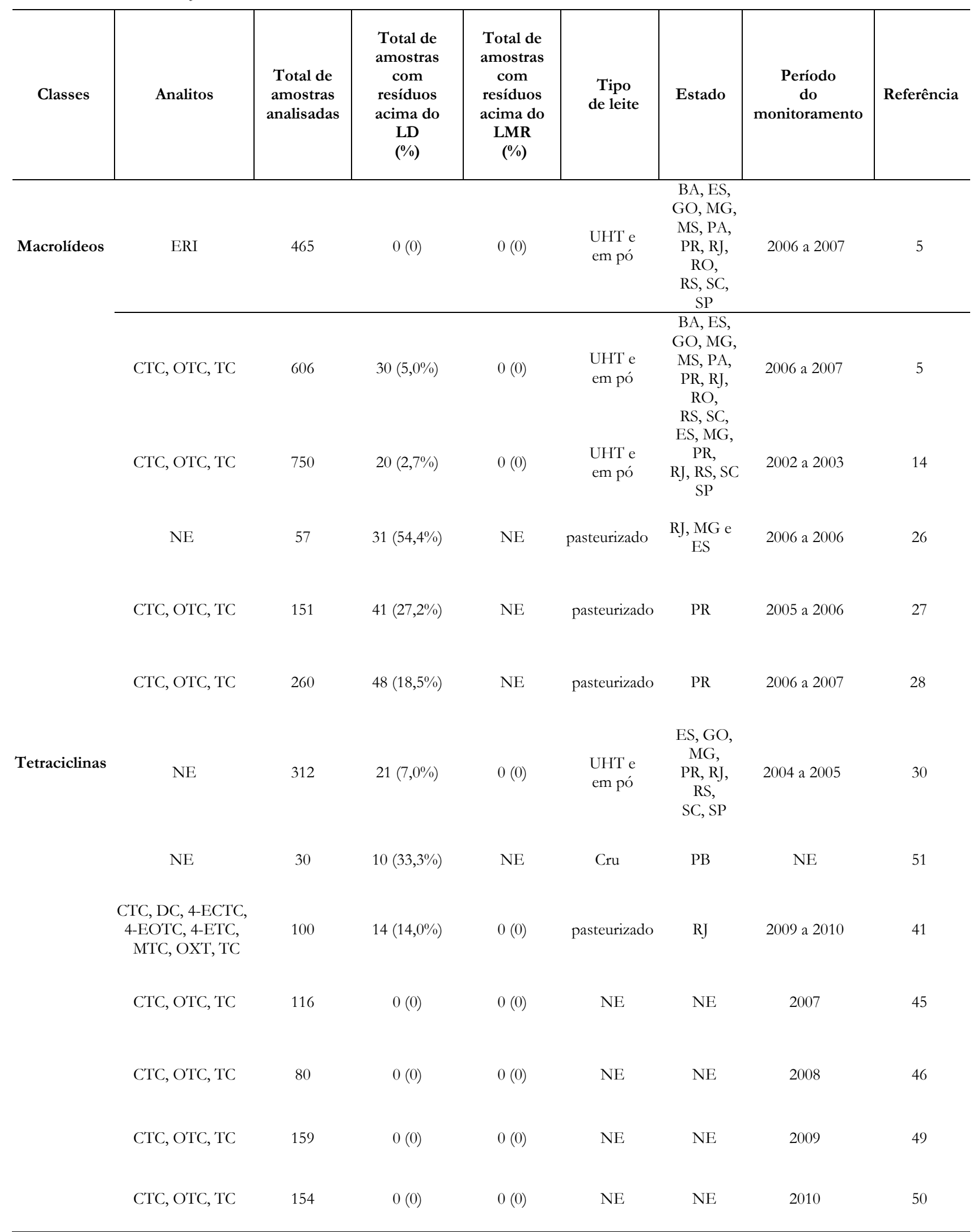

Continua 
Tabela 3. Continuação

\begin{tabular}{|c|c|c|c|c|c|c|c|c|}
\hline Classes & Analitos & $\begin{array}{c}\text { Total de } \\
\text { amostras } \\
\text { analisadas }\end{array}$ & $\begin{array}{c}\text { Total de } \\
\text { amostras } \\
\text { com } \\
\text { resíduos } \\
\text { acima do } \\
\text { LD } \\
(\%)\end{array}$ & $\begin{array}{c}\text { Total de } \\
\text { amostras } \\
\text { com } \\
\text { resíduos } \\
\text { acima do } \\
\text { LMR } \\
(\%)\end{array}$ & $\begin{array}{l}\text { Tipo } \\
\text { de leite }\end{array}$ & Estado & $\begin{array}{c}\text { Período } \\
\text { do } \\
\text { monitoramento }\end{array}$ & Referência \\
\hline & $\begin{array}{l}\text { SDMT, } \\
\text { SMTZ, } \\
\text { STAZ }\end{array}$ & 601 & $73(12,1 \%)$ & $0(0)$ & $\begin{array}{l}\text { UHT e } \\
\text { em pó }\end{array}$ & $\begin{array}{c}\text { BA, ES, } \\
\text { GO, MG, } \\
\text { MS, PA, } \\
\text { PR, RJ, } \\
\text { RO, } \\
\text { RS, SC, } \\
\text { SP }\end{array}$ & 2006 a 2007 & 5 \\
\hline & $\mathrm{NE}$ & 30 & $3(10,0 \%)$ & $\mathrm{NE}$ & Cru & $\mathrm{PB}$ & $\mathrm{NE}$ & 51 \\
\hline & $\begin{array}{l}\text { SDMT, } \\
\text { SMTZ, } \\
\text { STAZ }\end{array}$ & 65 & $0(0)$ & $0(0)$ & $\mathrm{NE}$ & $\mathrm{NE}$ & 2006 & 44 \\
\hline \multirow[t]{4}{*}{ Sulfonamidas } & $\begin{array}{l}\text { SDAZ, } \\
\text { SDMT, } \\
\text { SDPZ, } \\
\text { SMTZ, } \\
\text { SQNX, } \\
\text { STAZ }\end{array}$ & 67 & $0(0)$ & $0(0)$ & $\mathrm{NE}$ & $\mathrm{NE}$ & 2007 & 45 \\
\hline & $\begin{array}{l}\text { SDMT, } \\
\text { SMTZ, } \\
\text { STAZ }\end{array}$ & 56 & $0(0)$ & $0(0)$ & $\mathrm{NE}$ & $\mathrm{NE}$ & 2008 & 46 \\
\hline & $\begin{array}{l}\text { SDMT, } \\
\text { SMTZ, } \\
\text { STAZ }\end{array}$ & 61 & $0(0)$ & $0(0)$ & $\mathrm{NE}$ & $\mathrm{NE}$ & 2009 & 49 \\
\hline & $\begin{array}{l}\text { SDMT, } \\
\text { SMTZ, } \\
\text { STAZ }\end{array}$ & 76 & $0(0)$ & $0(0)$ & $\mathrm{NE}$ & $\mathrm{NE}$ & 2010 & 50 \\
\hline
\end{tabular}

NE: não especificado, AMOX: amoxicilina, AMPI: ampicilina, ANLD: ácido nalidixico, AOXL: ácido oxolinico, CFLP: cefalosporina, CFTF: ceftiofur, CFPN: cefapirina, CFPZ: cefoperazona, CFZL: cefazolina, CLFN: cloranfenicol, CPFX: ciprofloxacina, CTC: clortetraciclina, CLOX: cloxacilina, DC: doxiciclina, DCLO: dicloxacilina, DESTP: diidroestreptomicina, DFX: difloxacino, ERFX: enrofloxacina, ERI: eritromicina, ESTP: estreptomicina, 4-ECTC: 4-epiclortetraciclina, 4-EOTC: 4-epioxitetraciclina, 4-ETC: 4-epitetraciclina, FLFN: florfenicol, FMQN: flumequina, GEN: gentamicina, MTC: metaciclina, NEO: neomicina, OTC: oxitetraciclina, OXAC: oxacilina, OXC: axaciclina, PEN G: benzilpenicilina, PEN V: fenoximetilpenicilina, SCPD: sulfaclorpiridazina,SDAZ: sulfadiazina, SDMT: sulfadimetoxina, SDPZ: sulfadorpiridazina, SDX: sulfadoxina, SMRZ: sulfamerazina, SMTZ: sulfametazina, SMTX: sulfametoxazol, SQNX: sulfaquinoxalina, SRFX: saarafloxacina, STAZ: sulfatiazol, TAFN: tianfenicol, TC: tetraciclina, TIL: tilosina. 
Tabela 4. Resultado dos monitoramentos de antiparasitários relatados nas referências estudadas

\begin{tabular}{|c|c|c|c|c|c|c|c|c|}
\hline Classe & Analitos & $\begin{array}{c}\text { Total de } \\
\text { amostras } \\
\text { analisadas }\end{array}$ & $\begin{array}{l}\text { Total de } \\
\text { amostras } \\
\text { com } \\
\text { resíduos } \\
\text { acima do } \\
\text { LD (\%) }\end{array}$ & $\begin{array}{l}\text { Total de } \\
\text { amostras } \\
\text { com } \\
\text { resíduos } \\
\text { acima do } \\
\text { LMR (\%) }\end{array}$ & $\begin{array}{l}\text { Tipo } \\
\text { de leite }\end{array}$ & Estado & $\begin{array}{c}\text { Período do } \\
\text { monitoramento }\end{array}$ & Referência \\
\hline \multirow{8}{*}{ Avermectinas } & $\begin{array}{l}\text { ABA, } \\
\text { DOR, } \\
\text { IVE }\end{array}$ & 603 & $\begin{array}{c}23(3,8 \%) \\
57(9,45 \%) \\
284(47,1 \%)\end{array}$ & $\begin{array}{c}0(0) \\
9(1,5 \%) \\
0(0)\end{array}$ & $\begin{array}{l}\text { UHT e } \\
\text { em pó }\end{array}$ & $\begin{array}{c}\text { BA, ES, } \\
\text { GO, MG, } \\
\text { MS, PA, } \\
\text { PR, RJ, } \\
\text { RO, RS, } \\
\text { SC, SP }\end{array}$ & 2006 a 2007 & 5 \\
\hline & $\begin{array}{l}\text { ABA, } \\
\text { DOR, } \\
\text { IVE }\end{array}$ & 312 & $\begin{array}{c}24(7,7 \%) \\
3(1,0 \%) \\
123(39,0 \%)\end{array}$ & $\begin{array}{c}24(7,7 \%) \\
3(1,0 \%) \\
0(0)\end{array}$ & $\begin{array}{l}\text { UHT e } \\
\text { em pó }\end{array}$ & $\begin{array}{l}\text { ES, MG, } \\
\text { PR, RJ, } \\
\text { RS, SC, SP }\end{array}$ & 2003 & 14 \\
\hline & $\begin{array}{l}\text { ABA, } \\
\text { DOR, } \\
\text { IVE }\end{array}$ & 301 & $\begin{array}{c}34(11,0 \%) \\
2(0,7 \%) \\
169(56,0 \%)\end{array}$ & $\begin{array}{l}0(0) \\
0(0) \\
0(0)\end{array}$ & $\begin{array}{l}\text { UHT e } \\
\text { em pó }\end{array}$ & $\begin{array}{l}\text { ES, GO, } \\
\text { MG, PR, } \\
\text { RJ, RS, } \\
\text { SC, SP }\end{array}$ & 2004 a 2005 & 30 \\
\hline & IVE & 168 & $30(17,8 \%)$ & $0(0)$ & $\begin{array}{c}\text { pasteurizado } \\
\text { e UHT }\end{array}$ & $\mathrm{SP}, \mathrm{RJ}$ & 1999 a 2001 & 42 \\
\hline & $\begin{array}{l}\text { ABA, } \\
\text { DOR, } \\
\text { EPR, } \\
\text { IVE }\end{array}$ & 125 & $\begin{array}{c}0(0) \\
4(3,2 \%) \\
0(0) \\
2(1,6 \%)\end{array}$ & $\begin{array}{c}0(0) \\
4(3,2 \%) \\
0(0) \\
2(1,6 \%)\end{array}$ & $\mathrm{NE}$ & $\mathrm{NE}$ & 2006 & 44 \\
\hline & $\begin{array}{l}\text { ABA, } \\
\text { DOR, } \\
\text { EPR, } \\
\text { IVE }\end{array}$ & 86 & $\begin{array}{c}0(0) \\
0(0) \\
0(0) \\
1(1,2 \%)\end{array}$ & $\begin{array}{c}0(0) \\
0(0) \\
0(0) \\
1(1,2 \%)\end{array}$ & NE & $\mathrm{NE}$ & 2007 & 45 \\
\hline & $\begin{array}{l}\text { ABA, } \\
\text { DOR, } \\
\text { EPR, } \\
\text { IVE }\end{array}$ & 114 & $\begin{array}{c}0(0) \\
0(0) \\
0(0) \\
5(4,4 \%)\end{array}$ & $\begin{array}{c}0(0) \\
0(0) \\
0(0) \\
5(4,4 \%)\end{array}$ & NE & $\mathrm{NE}$ & 2008 & 46 \\
\hline & $\begin{array}{l}\text { ABA, } \\
\text { DOR, } \\
\text { EPR, } \\
\text { IVE, } \\
\text { MOX }\end{array}$ & 152 & $0(0)$ & $0(0)$ & NE & $\mathrm{NE}$ & 2011 & 47 \\
\hline \multirow{2}{*}{$\begin{array}{l}\text { Avermectinas } \\
\text { Benzoimidazol }\end{array}$} & $\begin{array}{l}\text { ABA, } \\
\text { DOR, } \\
\text { EPR, } \\
\text { IVE, } \\
\text { ABZ }\end{array}$ & 74 & $0(0)$ & $0(0)$ & $\mathrm{NE}$ & $\mathrm{NE}$ & 2009 & 49 \\
\hline & $\begin{array}{l}\text { ABA, } \\
\text { DOR, } \\
\text { EPR, } \\
\text { IVE, } \\
\text { MOX, } \\
\text { ABZ }\end{array}$ & 71 & $0(0)$ & $0(0)$ & NE & $\mathrm{NE}$ & 2010 & 50 \\
\hline
\end{tabular}

NE: não especificado. ABA: abamectina, ABZ: albendazol, DOR: doramectina, EPR:eprinomectina, IVE: ivermectina, MOX: moxidectina. 
O relatório de atividades do PAMVet de 2004/2005 descreve que das 312 amostras nas quais foram feitas análises de triagem para tetraciclinas, 21 apresentaram resíduos desta classe de antimicrobianos, mas os princípios ativos não foram confirmados nas análises por CLAE-UV [30].

A não confirmação de analitos em amostras que apresentaram resultados positivos na triagem pode ser explicada pelo fato dos métodos analíticos baseados em imunoensaios serem suscetíveis a interferência de metabólitos ou produtos de degradação dos analitos, os quais podem não ser identificados pelas técnicas cromatográficas utilizadas nos métodos de análises mais específicos. Ainda, os LD dos métodos de confirmação às vezes são maiores do que os dos métodos de triagem. A garantia da qualidade e a comparabilidade dos resultados analíticos originados por laboratórios aprovados para o controle oficial de resíduos é fundamental. Para isso, os laboratórios devem utilizar sistemas de garantia da qualidade e, especificamente, aplicar métodos validados em conformidade com procedimentos e critérios de desempenho comuns e garantir a rastreabilidade relativamente a normas comuns ou acordadas em comum [5].

No período de 2006/2007, das 30 amostras com resíduos acima do $\mathrm{LD}$ na triagem, o número de amostras com confirmação da presença de tetraciclinas por CLAE-UV/Visível foram, respectivamente, 12, 14 e 1 para tetraciclina, clortetraciclina e oxitetraciclina. $\mathrm{Na}$ confirmação de $\beta$-lactâmicos por CLAE-EM, foram detectados resíduos de cefapirina nas 6 amostras com resultados acima do LD na análise de triagem [5]. De 14 amostras de leite pasteurizado analisadas no período de 2009/2010 que obtiveram teores acima do LD, todas apresentaram resíduos de oxitetraciclina e em apenas 1 foi detectado também resíduo de tetraciclina ${ }^{[41]}$.

De 9 referências encontradas sobre monitoramentos de anfenicóis, 4 apresentaram dados de ocorrência de cloranfenicol e florfenicol em algumas amostras, porém apenas uma referência utilizou método de confirmação por CLAE-EM, confirmando a presença de cloranfenicol em apenas 3 amostras de leite UHT (Ultra High Temperature) e florfenicol em 2 amostras de leite em pó das 62 amostras de leite que apresentaram resultado acima do $\mathrm{LD}$ na triagem [5]. $\mathrm{O}$ cloranfenicol não tem LMR definido, pois seu uso em animais produtores de alimentos é proibido no Brasil e qualquer valor encontrado é considerado violação [43]. O florfenicol não possui LMR definido, pois não há legislação que autorize ou proíba o seu uso como medicamento veterinário para o gado leiteiro.

Embora muitas amostras tenham apresentado resíduos de antimicrobianos, apenas três referências apresentaram a ocorrência de amostras com resíduos em concentrações acima do LMR, cujos analitos foram a penicilina $G$, da classe dos $\beta$-lactâmicos e o aminoglicosídeo estreptomicina/diidroestreptomicina. Em uma das referências, das 43 amostras analisadas para determinação da penicilina $G$ pelo método CLAEDAD, 16 estavam acima do LMR [40]. $\mathrm{Na}$ outra, apenas uma amostra apresentou concentração acima do LMR para a penicilina $G$, das 84 amostras analisadas por CLAE-EM/EM [38]. Para a estreptomicina/diidroespectromicina, de 151 amostras somente uma $(0,7 \%)$ estava acima do LMR [2].

Analisando-se a Tabela 4 observa-se que das 10 publicações que registraram dados de monitoramento de resíduos de antiparasitários, 7 $(70,0 \%)$ apresentaram dados sobre a ocorrência de resíduos de ivermectina. Destas, apenas $3(30,0 \%)$ mostraram a ocorrência de abamectina e $4(40,0 \%)$ apontaram a presença de resíduos de doramectina.

A ocorrência de resíduos de antiparasitários com concentrações acima do LMR foi verificada em $1,6 \%{ }^{[44]}, 1,2 \%{ }^{[45]}$ e $4,4 \%{ }^{[46]}$ das amostras para ivermectina, $1,5 \% \quad[5], 1,0 \% \quad[14]$ e $3,2 \%$ [44] para doramectina e $7,7 \%{ }^{[14]}$ para abamectina. A ocorrência de resíduos acima do LMR nas amostras de leite demonstrou o não cumprimento das Boas Práticas Veterinárias. O MAPA adota medidas de educação sanitária aos produtores, quanto ao atendimento às boas práticas de uso de medicamentos veterinários, baseado nas violações detectadas [47]. Conforme preconizado pelo PAMVet, os laudos insatisfatórios foram encaminhados ao MAPA para providências e adoção de medidas corretivas, e os responsáveis pelas unidades fabris foram notificados pela Vigilância Sanitária do Estado [5].

\section{CONCLUSÃO}

Para que os resultados das análises de resíduos de antimicrobianos possam ser empregados como ferramentas de gestão de risco, a confiabilidade dos resultados é fundamental. Para isso, os métodos analíticos precisam ser validados de acordo com orientações internacionalmente aceitas e atingir limites 
de detecção e quantificação de forma a possibilitar a confirmação, a detecção e a quantificação adequada.

As análises de triagem são métodos qualitativos ou semiquantitativos e não especificam exatamente $\mathrm{O}$ analito. Muitos dos resultados das análises de resíduos de medicamentos veterinários ainda são inconclusivos devido à falta de confirmação dos resultados dos testes de triagem. Por isso, há uma necessidade de investimento em técnicas mais específicas para ensaios de confirmação nos laboratórios oficiais que prestam serviços de monitoramento destes resíduos.

O número de amostras analisadas em cada estudo variou de 20 a 10464. Uma amostragem tão variável dificulta uma avaliação comparativa dos resultados de ocorrência de resíduos.

Apesar do percentual de amostras com resultados analíticos acima do LD ter sido significativo, a exposição aos antimicrobianos pela ingestão de resíduos em leite parece representar, em geral, um baixo risco para a população brasileira, pois em 27 dos 35 trabalhos estudados $(77,2 \%)$, os níveis de antimicrobianos não atingiram os LMRs. Apenas 7 $(20,0 \%)$ das referências avaliadas apresentaram resultados insatisfatórios com relação à legislação brasileira.

Com relação aos antiparasitários, 5 de 10 referências $(50,0 \%)$ apresentaram resultados acima do LMR. Isto demonstra o descumprimento das Boas Práticas Veterinárias e de Fabricação pelos produtores de leite e indústrias, respectivamente. Portanto, o monitoramento de resíduos de medicamentos veterinários em alimentos é necessário, pois estes ainda continuam sendo utilizados intensivamente $e$ inadequadamente, como pode ser verificado pela detecção do cloranfenicol e de outros medicamentos veterinários em concentrações acima do LMR.

\section{REFERÊNCIAS}

[1] Fonseca LFL, Santos MV. Qualidade do leite e controle de mastite. São Paulo: Lemos Editorial; 2000.

[2] Brito MAVP, Lange CC. Resíduos de antibióticos em leite. Juiz de Fora: Embrapa Gado de Leite; 2000.
[3] Beltrane MA, Machinski Júnior M. Principais riscos químicos no leite: um problema de Saúde Pública. Arq Ciênc Saúde Unipar. 2005;9(2):141-45.

[4] Brasil. Instrução Normativa no 26, de 9 de julho de 2009. Aprova o Regulamento Técnico para a fabricação, o controle de qualidade, a comercialização e o emprego de produtos antimicrobianos de uso veterinário. Diário Oficial da União, Brasilia, 10 jul. 2009. Seção 1, p. 14.

[5] Brasil. Agência Nacional de Vigilância Sanitária. Programa de Análise de Resíduos de Medicamentos Veterinários em Alimentos de Origem Animal (PAMVet). Relatório de 2006 - 2007, Monitoramento de resíduos em leite expostos ao consumo (5ㅇ e $6 \underline{0}$ ano de atividades). Brasília (DF): Anvisa; 2009 [acesso em 8 nov 2012]. Disponível em: http://portal.anvisa.gov.br/wps/wcm/connect/72efdb0047 458ad19441d43fbc4c6735/PAMVET.pdf?MOD=AJPERE $\underline{\mathrm{S}}$

[6] Brasil. Instrução Normativa no 62, de 29 de dezembro de 2011. Aprova o Regulamento Técnico de Produção, Identidade e Qualidade do Leite Tipo A, o Regulamento Técnico de Identidade e Qualidade de Leite Cru Refrigerado, o Regulamento Técnico de Identidade e Qualidade de Leite Pasteurizado e o Regulamento Técnico da Coleta de Leite Cru Refrigerado e seu Transporte a Granel. Diário Oficial da União, Brasília, 30 dez. 2011. Seção 1, p. 6.

[7] Brasil. Lei no 9.782, de 26 de janeiro de 1999. Define o Sistema Nacional de Vigilância Sanitária, cria a Agência Nacional de Vigilância Sanitária, e dá outras providências. Diário Oficial da União, Brasília, 27 jan. 1999. Seção 1, p. 1.

[8] Mercado Comum do Sul. Resolução GMC no 54/2000. Regulamento Técnico Mercosul Metodologias Analíticas, Ingestão Diária Admissível e Limites Máximos de Resíduos para Medicamentos Veterinários em Alimentos de Origem Animal [acesso em 8 nov 2012]. Disponível em: http://www.mercosul.gov.br/normativa/resolucao/2000/m ercosul-gmc-res-no-54-00

[9] Brasil. Instrução Normativa no 12, de 10 de abril de 2001. Adota o Regulamento Técnico Mercosul Metodologias Analíticas, Ingestão Diária Admissível e Limites Máximos de Resíduos de Medicamentos Veterinários em alimentos de origem animal. Diário Oficial da União, Brasília, 12 abr. 2001. Seção 1, p. 10.

[10] Blasco C, Torres CM, Picó Y. Progress in analysis of residual antibacterials in food. Anal Chem. 2007;26(9):895913. 
[11] European Union. Commission Decision 2002/657/EC of 12 August 2002 implementing Council Directive $96 / 23 /$ EC concerning the performance of analytical methods and interpretation of results [cited 2012 Nov 8]. Available from: http://eurlex.europa.eu/LexUriServ/LexUriServ.do?uri=OJ:L:2002:22 1:0008:0036:EN:PDF

[12] Brasil. Instrução Normativa no 42, de 20 de dezembro de 1999. Altera o Plano Nacional do Controle de Resíduos em Produtos de Origem Animal - PNCR e os Programas de Controle de Resíduos em Carne - PCRC, Mel - PCRM, Leite - PCRL e Pescado - PCRP. Diário Oficial da União, Brasília, 22 dez. 1999. Seção 1, p. 213.

[13] Brasil. Resolução RDC no 253, de 16 de setembro de 2003. Cria o Programa de Análise de Resíduos de Medicamentos Veterinários em Alimentos de Origem Animal - PAMVet. Diário Oficial da União, Brasília, 18 set. 2003. Seção 1, p. 90.

[14] Brasil. Agência Nacional de Vigilância Sanitária. Programa de Análise de Resíduos de Medicamentos Veterinários em Alimentos de Origem Animal (PAMVet). Relatório de 2002 - 2003, Monitoramento de Resíduos em Leite Expostos ao Consumo (1으 e 2 음 ano de atividades). Brasília (DF): Anvisa; 2005 [acesso em 8 nov 2012]. Disponível em: http://portal.anvisa.gov.br/wps/wcm/connect/3a9ccc8047 $458 \mathrm{ad} 29445 \mathrm{~d} 43 \mathrm{fbc} 4 \mathrm{c} 6735 / 3$ relatorio 02 03.pdf?MOD $=\mathrm{AJ}$ PERES

[15] Codex Alimentarius. Veterinary Drug Maximum Residue Limits. [cited 2012 Nov 8]. Available from: http://www.codexalimentarius.net/mrls/vetdrugs/jsp/vetd q-e.jsp

[16] União Europeia. Regulamento (CE) no 6/2006. Limites máximos de resíduos de medicamentos veterinários nos alimentos de origem animal [acesso em 8 nov 2012]. Disponível em: http://vlex.pt/vid/prevhidroestreptomicina-tosilcloramida-36411013

[17] Food and Drug Administration. US Code of Federal Regulations: Tittle 21, Part 556, Section 500 (Chapter 1) Washington (DC): US Governmente Printing Office [cited 2012 Nov 8]. Available from: http://www.accessdata.fda.gov/scripts/cdrh/cfdocs/cfcfr/ $\underline{\text { CFRSearch.cfm?CFRPart }=556}$

[18] Nero LA, Mattos MR, Beloti V, Barros MAF, Franco BDGM. Resíduos de antibióticos em leite cru de quatro regiões leiteiras no Brasil. Ciênc Tecnol Aliment. 2007;27(2):391-93.
[19] Macedo LCS, Freitas JA. Ocorrência de resíduos de antimicrobianos em leite. Rev Ciênc Agrár. 2009;52:147-57.

[20] Folly MM, Machado SCA. Determinação de resíduos de antibióticos, utilizando-se métodos de inibição microbiana, enzimático e imunoensaios no leite pasteurizado comercializado na região norte do estado do Rio de Janeiro, Brasil. Cienc Rural. 2001;31(1):95-8.

[21] Tetzner TAD, Benedetti E, Guimarães EC, Peres RFG. Prevalência de resíduos de antibióticos em amostras de leite cru na região do Triângulo Mineiro, MG. Higiene Alimentar. 2005;19(130):69-72.

[22] Mendes CG, Sakamoto SM, Silva JBA, Leite AI. Pesquisa de resíduos de beta-lactâmicos no leite cru comercializado clandestinamente no município de Mossoró, RN, Utilizando o Delvotest SP. Arq Inst Biol. 2008;75(1):958.

[23] Nunes MT, D’Angelino JL. Ocorrência de resíduos de antibióticos no leite, em fazendas produtoras e no leite pronto para consumo. Higiene Alimentar. 2007;21(149):5761.

[24] Becker TA, Negrelo IF, Racoulte F, Drunkler DA. Avaliação da qualidade sanitária de leite integral informal, pasteurizado, UHT e em pó comercializados na cidade de Medianeira e Serranópolis do Iguaçu - Paraná. Semina: Ciências Agrárias. 2010;31(3):707-16.

[25] Porto CR, Anselmo MS, Timm CD, Gonzalez HL, Oliveira DS, Alexis MA, et al. Ocorrência de resíduos de antibióticos beta-lactâmicos no leite cru entregue à indústria na região sudeste do Rio grande do Sul. Rev Inst Latic “Cândido Tostes". 2002;57(327):313-16.

[26] Morais CMQJ, Durães TS, Nóbrega AW, Jacob SC. Presença de resíduos de antibióticos em leite bovino pasteurizado. Ciênc Tecnol Aliment. 2010;30(Suppl. 1):33-5.

[27] Bando E, Oliveira RC, Ferreira GMZ, Machinski Júnior M. Occurrence of antimicrobial residues in pasteurized milk commercialized in the state of Paraná, Brazil. J Food Prot. 2009;72(4):911-14.

[28] Zanella GN, Mikcha JMG, Bando E, Siqueira VLD, Machinski Júnior M. Occurrence and antibiotic resistance of Coliform Bacteria and antimicrobial residues in pasteurized cow's milk from Brazil. J Food Prot. 2010;73(9):1684-87.

[29] Almeida LP, Vieira RL, Rossi DA, Carneiro AL, Rocha ML. Resíduos de antibióticos em leite de propriedades rurais da região de Uberlândia-MG. Biosci J. 2003;19(3):83-7. 
[30] Brasil. Agência Nacional de Vigilância Sanitária. Programa de Análise de Resíduos de Medicamentos Veterinários em Alimentos de Origem Animal (PAMVet). Relatório de 2004 - 2005, Monitoramento de Resíduos em Leite Expostos ao Consumo (3으 e 40 ano de atividades). Brasilia (DF): Anvisa; 2006 [acesso em 8 nov 2012]. Disponível em: http://portal.anvisa.gov.br/wps/wcm/connect/5e49528047 4582488e55de3fbc4c6735/relatorio leite 200405.pdf?MOD=AJPERES

[31] Oliveira RC, Paschoal JAR, Reyes FGR. Streptomycin and dihydrostreptomycin residues in bovine milk from the Brazilian retail market. Food and Additives and Contaminants: Part B. 2010;3(3):156-62.

[32] Nascimento GGF, Maestro V, Campos MSP. Ocorrência de resíduos de antibióticos no leite comercializado em Piracicaba, SP. Rev Nutr. 2001;14(2):11924.

[33] Borges GT, Santana AP, Mesquita AJ, Mesquita SQP, Silva LAF, Nunes VQ. Ocorrência de resíduos de antibióticos em leite pasteurizado integral e padronizado produzido e comercializado no estado de Goiás. Ciência Animal Brasileira. 2000;1(1):59-63.

[34] Biacchi NC, Jorge AOC, Ueno M. Detecção de resíduos antibióticos em leite bovino na região do vale do Paraíba, São Paulo. Rev Biociên. 2004;10(1-2):47-9.

[35] Sousa FC, Oliveira ENA, Santos DC, Silva EFM. Ocorrência de resíduos de antibióticos em leites pasteurizados comercializados no estado do Ceará - Brasil. Revista Verde. 2010;5(4):10-4.

[36] Fonseca GP, Cruz AG, Faria JAF, Silva R, Moura MRL, Carvalho LMJ. Antibiotic residues in Brazilian UHT milk: a screening study. Ciênc Tecnol Aliment. 2009;29(2):451-53.

[37] Barros GMS, Jesus NM, Silva MH. Pesquisa de resíduos de antibióticos em leite pasteurizado tipo C, comercializado na cidade de Salvador. Rev Bras Saúde Prod An. 2001;2(3):69-73.

[38] Jank L, Hoff RB, Tarouco PC, Barreto F, Pizzolato TM. $\beta$-lactam antibiotics residues analysis in bovine milk by LCESI-MS/MS: a simple and fast liquid-liquid extraction method. Food Additives and Contaminants: Part B. 2012;29(4):497-507.

[39] Mamani MCV, Reyes FGR, Rath S. Multiresidue determination of tetracyclines, sulphonamides and chlramphenicol in bovine milk using HPLC-DAD. Food Chem. 2009;117(3):545-52.
[40] Carlos LA, Cordeiro CAM, Folly MM, Martins MLL. Avaliação físico-química, microbiológica e de resíduos de penicilina, em leite tipo " $C$ " comercializado no município de Campos dos Goytacazes, RJ. Higiene Alimentar. 2004;18(123):57-61.

[41] Spisso BF, Monteiro MA, Pereira UM, Ferreira RG, Costa RP, Cruz TA, et al. Pilot survey of commercial pasteurized milk consumed in the metropolitan area of Rio de Janeiro, Brazil, for tetracyclines residues, including the 4epimers of oxytetracycline, tetracycline and chlortetracycline. Food Additives and Contaminants: Part B. 2010;3(4):220-27.

[42] Lobato V, Rath S, Reyes FGR. Occurrence of ivermectin in bovine milk from the Brazilian retail market. Food Additives and Contaminants. 2006;23(7):668-73.

[43] Brasil. Portaria no 193, de 12 de maio de 1998. Aprova o Regulamento Técnico para o licenciamento e a renovação de licença de antimicrobianos de uso veterinário. Diário Oficial da União, Brasília, 13 maio 1998. Seção 1, p. 114.

[44] Brasil. Instrução Normativa no 8 , de 30 de março de 2007. Publica os resultados do acompanhamento dos Programas de Controle de Resíduos e Contaminantes em Carnes (Bovina, Suína, Aves e Equina), Leite, Ovos, Mel e Pescado do exercício de 2006. Diário Oficial da União, Brasilia, 03 abr. 2007. Seção 1, p. 1.

[45] Brasil. Instrução Normativa no 9, de 10 de abril de 2008. Publica os resultados do acompanhamento dos Programas de Controle de Resíduos e Contaminantes em Carnes (bovina, suína, aves e equina), Leite, Ovos, Mel e Pescado do exercício de 2007. Diário Oficial da União, Brasília, 17 abr. 2008. Seção 1, p. 28.

[46] Brasil. Instrução Normativa no 15 , de 25 de maio de 2009. Publica os resultados do monitoramento dos Programas de Controle de Resíduos e Contaminantes em Carnes (bovina, suína, aves e equina), Leite, Ovos, Mel e Pescado do exercício de 2008. Diário Oficial da União, Brasilia, 28 de maio 2009. Seção 1, p. 31.

[47] Brasil. Instrução Normativa no 7, de 4 de abril de 2012. Publica os resultados do acompanhamento dos Programas de Controle de Resíduos e Contaminantes dos subprogramas de monitoramento exploratório em Carnes (Bovina, Suína, de Aves e Equina), em Leite, Ovos, Mel e Pescado do exercício de 2011. Diário Oficial da União, Brasília, 05 abr. 2012. Seção 1, p. 12.

[48] Villa FB, Pinto JPAN. Qualidade físico-química, microbiológica e presença de resíduos de antimicrobianos, no leite in natura comercializado informalmente em Brotas, SP. Higiene Alimentar. 2008;22(158):98-103. 
[49] Brasil. Instrução Normativa no 6, de 16 de março de 2010. Publica os resultados do acompanhamento dos Programas de Controle de Resíduos e Contaminantes em Carnes (bovina, suína, aves e equina), Leite, Ovos, Mel e Pescado do exercício de 2009. Diário Oficial da União, Brasília, 23 mar. 2010. Seção 1, p. 8.

[50] Brasil. Instrução Normativa no 6 , de 25 de fevereiro de 2011. Publica os resultados do acompanhamento dos Programas de Controle de Resíduos e Contaminantes dos subprogramas de monitoramento exploratório em Carnes (bovina, suína, aves e equina), Leite, Ovos, Mel e Pescado do exercício de 2010. Diário Oficial da União, Brasília, 28 fev. 2011. Seção 1, p. 4

[51] Medeiros NGA, Carvalho MGX, Santos MGO, Lima SCP. Detecção de antibióticos no leite in natura consumido no município de Patos, Paraíba. Higiene Alimentar. 2004;18(124):85-8. 